\title{
América Latina dentro del orden económico mundial
}

\section{INTRODUGGión}

La idea principal que inspira estas líneas es demostrar que la articulación de la economía latinoamericana con los países industrializados de economía de mercado así como con los países socialistas llegó a su punto máximo en torno a los años 1980 y 1981 y que en el mismo tiempo que media hasta el término del presente decenio, quizá hasta el año 2000, esa relación se mantendrá estancada. Debido a ello, América Latina no tendrá más opción que intensificar la cooperación económica y los intercambios comerciales dentro del continente y, en menor grado, con los países de Africa y de Asia ${ }^{1}$.

Las modalidades de la inserción de América Latina en la economía mundial han cambiado en el curso de los últimos decenios en función de la dinámica cle las transformaciones que se han produ. cido en el contexto de la economía mundial. Los Estados Unidos han disminuido su participación en las exportaciones mundiales totales y, particularmente, en el caso de los productos manufacturados; lo mismo ha ocurrido con la economía británica. Por otro lado, las exportaciones de la República Federal de Alemania y del Japón han aumentado considerablemente. En cuanto a Francia, su participación se ha mantenido estable y aquella correspondiente a los países en desarrollo se ha reducido, por su lado, en una proporción importante. En efecto, la participación de América Latina en el total de exportaciones mundiales, que era del $11 \%$ en 1950 , disminuyó al $7 \%$ en 1970 y al $4,5 \%$ en $1981^{2}$.

Esto no significa que América Latina haya perdido su importancia económica. Su población asciende a 360 millones de habitantes,

*El autor del presente estudio ocupa el cargo de Director en el Departamento de Asuntos Económicos y Sociales Internacionales de las Naciones Unidas. Las opiniones vertidas aquf son de su entera y exclusiva responsabilidad.

ISobre este tema publiqué ya un artículo titulado "La cooperación económica entre pafses en desarrollo. Necesidad de un diálogo Sur-Sur", Nueva Sociedad", No 60, Garacas, 1982.

"Según informaciones de las Naciones Unidas. 
el PNB Iatinoamericano no ha cesado de aumentar y la presencia de América Latina en la economía mundial es un hecho irrefutable ${ }^{3}$. Desde otro punto de vista, América Latina representa un mercado de enorme magnitud: en 1981 su capacidad de importación se acercaba a los 100 millones de dólares; su demanda de productos manufacturados y de bienes de capital no puede ser subestimada por los países industrializados ni por los demás países en desarrollot.

La dirección que sigue el comercio latinoamericano se concentra en los países industrializados de economía de mercado. En 1980, del total de exportaciones latinoamericanas, el $33 \%$ correspondía a los Estados Unidos, el $16 \%$ a la Comunidad Económica Europea (CEE) y el $5,1 \%$ al Japón. Los países de la Organización de Cooperación y Desarrollo Económicos (OCDE) absorben aproximadamente el $68 \%$ de las exportaciones de América Latina. A Ios países socialistas les corresponde solamente el 6,5\% de las exportaciones totales ${ }^{5}$. En lo que respecta a las importaciones latinoamericanas, en 1980, del total, el $60 \%$ procedía de los países industrializados, del cual el $36 \%$ de 10 s Estados Unidos, el $15 \%$ de la ceE y el $7 \%$ del Japón. A los países socialistas de Europa Central les correspondía solamente el 0,7\%\%.

Las inversiones directas de los Estados Unidos en América Latina ascendieron a 37.000 millones de dólares en 1979. Las inversiones de los países de la ocDE en conjunto (exceptuando el Japón) habían alcanzado un total de 51.000 millones de dólares a fines de 1978. Las inversiones directas de los Estados Unidos representaron las dos terceras partes de las inversiones directas hechas en América Latina durante los años 1977 y 1978. Sin embargo, en el período 1978-1979, del total de inversiones estadounidenses en el mundo, a América Latina le correspondió el 20\%. En el caso de la República Federal de Alemania y del Japón, sus inversiones en América Latina representaron entre el 13 y el $15 \%$ de aquellas efectuadas en el mundo entero?. En el caso de las inversiones mundiales de los países en desarrollo, a América Latina le correspondió el $60 \%$ de las inversiones directas hechas entre 1975 y 1980; en el de las inversiones de los Estados Unidos en los países en desarrollo, a América Latina le correspondió el 80\% en el período 1978-1979. En el de la República Federal de Alemania el $50 \%$ y en el del Japón el $30 \%{ }^{8}$. En 1979 las inversiones directas se concentraron en los principales paí-

'La proyección del crecimiento demográfico da una población de 610 millones de habitantes en América Latina el año 2000.

"Pese a que su capacidad se ha reducido en 1982.

Tnformación del canre.

Ibid.

T"ELA, "América Latina y Estados Unidos: el papel de las empresas transnacionales", Doc. SP/RC/A/-EU/I/DT NO I, 24 de septiembre de 198I, p. 5.

sIbid, p. 9. 
ses latinoamericanos; el $27 \%$ en el Brasil, el $12 \%$ en México, el $7 \%$ en Venezuela y la Argentina y el $6 \%$ en Panamá.

Las inversiones directas de los Estados Unidos estuvieron financiadas por empresas transnacionales. Es preciso mencionar un aumento gradual de éstas en los sectores financieros, las cuales han superado rápidamente a las inversiones en los sectores productivos (industria, petróleo y minerales) ${ }^{10}$. Las empresas transnacionales de los Estados Unidos realizaron ventas a América Latina por un total de 57,3 millones de dólares en 1975, casi el 1\% del PNB latinoamericano de ese año11. En 1979, las filiales en América Latina de las empresas transnacionales de los Estados Unidos abonaron a sus casas matrices 400 millones de dólares por concepto de cánones y regalías (derechos), de Ios cuales el $40 \%$ correspondió a las filiales de bancos transnacionales de los Estaclos Unidos respecto del total abonado por el sector industrial ${ }^{12}$. La relación entre utilidades y valor ncumulado de las inversiones aumentó entre 1976 y 1979.

Las cifras citadas más arriba son ilustrativas de la situación general de América Latina dentro del orden económico mundial en torno al decenio de 1980. Muestran cierto distanciamiento con la economía estadounidense en el caso del comercio de exportación e importación, pero una dependencia singular respecto de las inversiones directas de los Estados Unidos y de las empresas transnacionales de ese país.

\section{AMÉRICA LATINA EN EL MARGO DE IA ACTUAL GRISIS DEL ORDEN EGONÓIIICO MUNDIAL}

En este orden de ideas, posiblemente proceda hacer aquí un somero análisis de las tendencias principales de la coyuntura económica actual de América Latina y de sus problemas estructurales.

Los síntomas de tal coyuntura son dramáticos ${ }^{13}$. El producto interno bruto de América Latina disminuyó en 1982 alrededor de un $1 \%$, lo que no había ocurrido desde hacía casi 40 años. Esa disminución, unida al factor población, equivale a una reducción del $3 \%$ del producto per cápita y afecta a la mayoría de los países latinoamericanos. En el caso de los países no exportadores de petróleo, los términos de intercambio no habian registrado un nivel tan bajo desde hacía 50 años. La tasa de desempleo es una de las más altas desde que se empezó a llevar una estadística del número de desempleados. La crisis financiera ha adquirido una envergadura sin

Ibid, p. I0.

1olbid, p. 10

Ibid, p. 7 .

IeTbid, p. 8.

${ }^{13}$ Las cifras siguientes provienen de la GEPAL. 
precedentes y traído consigo el desplome de la mayor parte de las monedas latinoamericanas, generándose así nuevas presiones inflacionarias que han acrecentado en aproximadamente el $80 \%$ el indice medio de los precios de venta al consumidor, lo que supera todas las cotas alcanzadas en el pasado. Otra cifra sin precedentes, la del déficit de la balanza de pagos, es ya de 14 mil millones de ciólares. La deuda exterior ha ascendido a 270 millones de dólares y los desembolsos netos por concepto de intereses y de utilidades han rebasado los 34 mil millones de dólares anuales, o sea el doble que dos años antes. Los ingresos netos de capitales en América Latina han pasado de 42 mil millones de dólares en 1981 a 19.200 millones en 1982. Esto por lo que se refiere a los indicadores regionales.

América Latina sigue siendo un continente exportador de materias primas no elaboradas e importador, sin embargo, de productos manufacturados, bienes de equipo y capitales. Es innegable que actualmente exporta más productos manufacturados que antes y que el petróleo representa uno de los pilares de la exportación, pero esos aspectos positivos no han alterado la índole de su dependencia.

Los precios medios de los productos básicos (exceptuados los combustibles) en dólares corrientes han disminuido en un $16 \%$ de 1980 a 1981 y nuevamente en un $16 \%$ de 1981 a 1982 . En el caso de los precios de los principales productos de exportación latinoamericanos, que en conjunto representan una proporción considerable de los ingresos totales por concepto de exportaciones, la baja registrada entre el 19 de enero de 1980 y el 31 de diciembre de 1982 fue la siguiente: café, 20\%; azúcar, $70 \%$ cobre, $32 \%$; carne de vacuno, $25 \%$; algodón, 22\%; mineral de hierro, $4 \%$; soja, $18 \%$; cacao, 33\%; maíz, 34\%; harina de pescado, 32\%; lana, 20\%; y estaño, $24 \%$. Ciertos precios han escapado a esta tendencia del periodo, particularmente el de los plátanos y el de la bauxita, los cuales han aumentado, respectivamente, en un $5 \%$ y un $0,6 \%$. Si se considera esa tendencia de los precios expresándola en términos de dólares constantes, la baja resulta todavía más acentuada. En efecto, en el caso de un número considerable de productos, los precios constantes de 1982 se situaban por debajo de la mitad de sus niveles de 1950. El hundimiento de la demanda como consecuencia de la recesión de las economías industriales (que siguen absorbiendo cerca del $70 \%$ de las exportaciones de productos básicos procedentes de los países en desarrollo) ha influido desfavorablemente en el volumen total de las exportaciones latinoamericanas, las cuales habian registrado un ritmo de expansión anual media elevado y sostenido, del 8,7\%, entre 1976 y 1981 , pero se han estancado completamente en 1982. Si se tiene presente que los productos básicos representan aún cerca del $80 \%$ del valor total de las exportaciones latinoamericanas (y cerca del 40\% si no se cuenta entre ellos al petróleo), el 
impacto de esa baja de los precios en las economías de los países de la región ha sido considerable.

Cabe añadir que la reducción del valor de las exportaciones (que ascendia al $10 \%$ en el caso de los bienes en conjunto) ha determinado una contracción de las importaciones no latinoamericanas del orden del $19 \%$. Como consecuencia de ello se ha creado un excedente de la balanza comercial de bienes. Al mismo tiempo, los términos del intercambio se han deteriorado en un 7\%\%. Además, la demanda latinoamericana de productos de la CEE, de los Estados Unidos, del Japón y de otros paises ha disminuido en un 19\%. Conviene subrayar el hecho siguiente: que la baja de los precios de las materias primas y la degradación de los términos de intercambio han desembocado en una disminución de las importaciones, fenómeno este que ha afectado incluso al aparato industrial de los países industrializados.

América Latina atraviesa actualmente la crisis económica más grave que ha conocido desde el término de la Segunda Guerra Mundial. Tal crisis es igualmente la más profunda y la más compleja sufrida por ella con posterioridad a la gran depresión del decenio de 1930. En efecto, dicha crisis ha afectado, de diversas maneras, : la casi totalidad de los países latinoamericanos e incidido no solamente en la esfera de la producción y los servicios sino también en la de las finanzas y el comercio.

Sin embargo, América Latina no es la única que padece esa crisis. El mundo industrializado (denominado "el centro"), al que por su historia se halla ligada América Latina, tampoco ha esccapado de ella. A grandes rasgos, la crisis internacional ha afectado a los países de América Latina y la crisis latinoamericana repercute en las economías centrales. Volveremos a encontrar esa interacción a todo lo largo del análisis que sigue. Es pues en un contexto de crisis gèneralizada como debe examinarse el punto de vista latinoamericano en el establecimiento de un nuevo orden económico internacional.

En otras palabras, es preciso estudiar las características del sistema actual de relaciones económicas internacionales, sus problemas estructurales fundamentales así como su coyuntura actual, con objeto de ver cuáles son los cambios esenciales que habría que introducir para poder modificar las relaciones económicas tradicionales y forjar nuevos tipos de relaciones cuya denominación en términos generales es el nuevo orden económico internacional. El obstáculo principal es el que plantea la elaboración de un conjunto de polfticas y de medidas que permitan asegurar, en un periodo de crisis generalizada, el paso desde un orden injusto e ineficaz hacia otro más equitativo y eficiente. Son esos los temas que abordaré en las secciones siguientes. 
Gonzalo Martner G. / América Latina dentro del orden económico...

\section{RELACTONES ECONÓMICAS CON LOS ESTADOS UNIDOS}

El análisis específico de las relaciones económicas de América Latina exige ciertos comentarios previos sobre su articulación con la economía de los Estados Unidos. En primer lugar, hay que analizari brevemente algunas grandes transformaciones del sistema de relaciones exteriores de la economía de los Estados Unidos que se han producido en el curso de los últimos decenios. Habrá que hacer al misino tiempo ciertos comentarios sobre la evolución de la propia economía estadounidense.

Los Estados Unidos han perdido su importancia relativa en el producto nacional bruto (PNB) mundial. En 1955 les correspondía el $40 \%$, en tanto que en 1980 tal porcentaje disminuía a un $23 \% \%^{14}$ Lo mismo les ha ocurrido en el marco de los países industrializados de economía de mercado, caso en el cual les correspondió el $57 \%$ en 1955, pero tan sólo el $40 \%$ en 1980. La parte correspondiente a Ios Estados Unidos en el comercio mundial tambien ha disminuido considerablemente. En efecto, dicha parte, que era del $15,4 \%$ en 1970, se redujo al 11,9\% en 1980. En el caso del sector de las exportaciones industriales, su parte ha disminuido igualmente, del $21,3 \%$ en 1970 al $17,9 \%$ en 1980 . Cabe afirmar por tanto que los Estados Unidos no constituyen ya un poder regulador de la economfa mundial en el decenio de 1980.

La economía interna de los Estados Unidos ha cambiado enormemente. De una economía de producción de bienes (ésta representaba el $46 \%$ del PNB en 1928) se ha transformado con el paso de los años en una economía de servicios, sector éste al que corresponde el $66 \%$ del PNB en 1980. Como consecuencia de ello, el crecimiento de la economía estadounidense depende hoy en día más del capital humano que de la acumulación de capital físico.

Esto significa que les es preciso acordar prioridad al mejoramiento de la gestión de los servicios, introducir cambios en el aprovechamiento de los recursos, adquirir nuevos conocimientos técnicos, implantar mejores sistemas de información y recurrir a computadoras en lo que atañe a la adopción de decisiones, al desarrollo de capacidades nuevas, al entrenamiento masivo del personal dirigente, a la modificación de la actitud sïcológica de los inversionistas y de los empresarios, etc.

Como resultado de ello, el crecimiento del PNB ha quedado algo disociado de la acumulación física de capital. Es esa la razón por la cual la economía estadounidense tiene una menor necesidad de materias primas para su desarrollo.

\footnotetext{
${ }^{1}$ Las cifras citadas en esta seccion son las dadas por el Ministerio de Comercio de Ios Estados Unidos en "Highlights of us Export and Import Trade".
} 
Es menester añadir que en estos últimos años dicho cambio se está produciendo en un contexto de internacionalización constante de la economía estadounidense. Ha habido un proceso de apertura de ella: en 1946 las exportaciones e importaciones de los Estados Unidos no representaban sino el 4\% del PNB; en 1980 ese porcentaje se elevaba al $15 \%$. Sin embargo, como se indicó ya, tal apertura de la economfa estadounidense no se ha traducido en un aumento de su importancia relativa en las exportac:ones mundiales.

Al mismo tiempo, durante estos diez años (1973-1983) la economia estadounidense ha registrado una pérdida de dinamismo y una inestabilidad significativa. La frecuencia de las recesiones ha sido acelerada por factores estructurales profundos; la crisis de 1969-1970 fue seguida por la de 1978-1975 y, tras una recuperación pasajera, se produjo la de 1979-1980 y luego ha surgido una nueva recesión que se inició en julio de 1981 y que sigue haciendo estragos en el presente año 1983. En resumidas cuentas, en una docena de años se han sucedido cuatro recesiones.

Lo que parece evidente es que hemos llegado al término de la era de expansión dinámica y estable de la economía estadounidense, cuya tasa de crecimiento anual, que en el curso del decenio de 1960 había llegado a ser del orden del 4,2\%, se redujo al $3,1 \%$ en el decenio de 1970 y disminuyó hasta el $-1,8 \%$ en 1982, que es el nivel más bajo de derrumbamiento desde 1946. La productividad, que progresaba a una tasa anual del $3,1 \%$ en el decenio de 1960 , no aumentó sino del $1,6 \%$ en el curso del decenio de $1970 \mathrm{y}$, si se exceptúa una ligera recuperación en 1981, esa tasa anual ha pasado a ser negativa a partir de 1978. El tipo de interés básico cobrado por los bancos, que era del $4,5 \%$ en 1959 , subió al $8 \%$ en 1969 , al $12,75 \%$ en 1979 y al $21,5 \%$ en diciembre de 1980 . El desempleo, que afectaba al $4,5 \%$ de la población activa en el curso de los decenios de 1950 y 1960, afectaba al 6,2\% en el curso deI decenio de 1970. A principios del decenio de 1980, dicho porcentaje se situaba en torno al $9 \%$ y ascendía, en diciembre de 1982 , al $11,4 \%$. El fndice de los precios de venta al consumidor, que era del $2 \%$ entre 1950 y finales del decenio de 1960, aumentó en el curso del de 1970 hasta alcanzar una tasa anual de aproximadamente el $7,1 \%$ y deI $12,9 \%$ al iniciarse el decenio de 1980 , disminuyendo luego al $9,5 \%$ en 1981 y al $6 \%$ en 1982. Probablemente ese índice representa el único signo indicativo de una mejora. El precio pagado para moderar la inflación es indudablemente elevado y resulta posible que entrañe incluso la pérdida del rango de país motor del dinamismo del resto de la economía mundial.

La acumulación de contradicciones inherentes a la marcha de la economía estadounidense tiene diversos origenes: por una parte, Ios tipos de interés elevados han determinado un alza del valor del dólar y, por ende, un encarecimiento de sus exportaciones, lo que ha 
Gonzalo Martner G. / América Latina dentro del orden éconómico...

traf́do consigo que el déficit comercial de 1982 se dispare a $42 \mathrm{mi}$ llones de dólares (cifra sin precedentes), y se prevé que tal cifra se duplique en 1983, Ese estado de cosas frena evidentemente las po: sibilidades de recuperación, puesto que la demanda exterior se ha debilitado.

Las relaciones entre la economía de los Estados Unidos y América Latina han cambiado después de la Segunda Guerra Mundial. En efecto, los Estados Unidos han acrecentado sus relaciones económicas con los países de Europa Occidental, de Asia y de Africa. De esos diferentes países han obtenido una proporción creciente de productos básicos e incluso productos manufacturados, desinteresándose de los productos latinoamericanos. Según informaciones procedentes del Ministerio de Comercio, los Estados Unidos han adquirido solamente el $15 \%$ de sus importaciones en América Latina.

Por otra parte, América Latina ha aumentado sus exportaciones a los países europeos, al Japón y a los países socialistas, al tiempo que ha ampliado su mercado interno. En 1980, América Latina no exportaba a los Estados Unidos más que el $33 \%$ de sus exportaciones totales y tan sólo el $25 \%$ si se excluye al petróleo. Esto significa que hay una lenta y paulatina disyunción comercial de la economía de América Latina respecto de la economía de los Estados Unidos. Tal fenómeno no tiene, empero, un carácter homogéneo entre los países latinoamericanos y los geográficamente próximos a los Estados Unidos que exportan a ese país, en ciertos casos, las dos terceras partes de sus exportaciones totales, como ocurre en el caso de México, de Trinidad y Tobago, de la República Dominicana y de otros países del Caribe. Esa proporción disminuye al avanzar hacia el Sur y, en el caso del Brasil, sólo es del 17\%, en Colombia del $28 \%$ y del $38 \%$ en Venezuela. En el caso del Cono Sur de América Latina (la Argentina, Chile y el Uruguay), dichas exportaciones representan úmicamente el $10 \%$ de sus exportaciones totales.

Otro cambio que hay que mencionar es la transformación de América Latina, que era una región exportadora de productos tropicales, en una región exportadora de productos que revisten una gran importancia económica.

Como se advierte en el Cuadro 1, en 1980 el petróleo representaba el $51 \%$ del valor de las exportaciones de América Latina a los Estados Unidos y los productos manufacturados el $23 \%$, o sea que los combustibles y las manufacturas representan hoy en día el $75 \%$ de las exportaciones latinoamericanas a los Estados Unidos. De 1970 a 1980, el porcentaje correspondiente a la exportación de productos alimentarios disminuía del $41 \%$ a tan sólo el $21 \%$ y también disminuía el de la exportación de minerales y otros productos en bruto, que pasaba del $10 \%$ al $4 \%$. Estamos persuadidos de que esa modificación en la composición de los productos exportados a 
los Estados Unidos por América Latina asegura a ésta una capacidad de negociación en el curso del presente decenio con la que jamás había contado en su historia pasada.

\section{Guadro 1}

\section{IMPORTACIONES DE LOS ESTADOS UNIDOS PROCEDENTES DE AMÉRICA LATINA}

(En millones de dólares corrientes)

\begin{tabular}{lrrrrrrrr}
\hline & 1970 & $\%$ & 1975 & $\%$ & 1979 & $\%$ & 1980 & $\%$ \\
\cline { 2 - 8 } & & & & & & & \\
& & & & & & & & \\
Alimentos y bebidas & 2.387 & 40,9 & 3.950 & 24,7 & 7.678 & 25,1 & 7.941 & 21,4 \\
Aceites y grasas & 23 & 0,4 & 43 & 0,2 & 54 & 2 & 63 & 0,1 \\
$\begin{array}{l}\text { Materias primas } \\
\text { Combustibles }\end{array}$ & 623 & 10,7 & 1.123 & 7,0 & 1.485 & 4,9 & 1.590 & 4,3 \\
$\begin{array}{l}\text { Productos manufac- } \\
\quad \text { dos y otros }\end{array}$ & 1.157 & 28,2 & 7.641 & 47,6 & 18.734 & 45,1 & 18.921 & 51,1 \\
$\begin{array}{l}\text { Total de las impor- } \\
\text { taciones procedentes } \\
\text { de América Latina }\end{array}$ & 5.839 & 100,0 & 16.040 & 100,0 & 30.483 & 100,0 & 37.034 & 100,0 \\
\hline
\end{tabular}

Fuente: Ministerio de Comercio, "Highlights of u.s. Export and Import Trade".

Es dable concluir, por una parte, que la economía estadouniden. se ha pasado por numerosas transformaciones estructurales internas de gran importancia en el curso de los últimos decenios y que la importancia relativa de sus exportaciones mundiales ha disminuido, $y$, por otra, que en compensación trata de aumentar su influencia en el sistema financiero mundial. Simultáneamente, América Latina ha registrado cambios significativos: el PNB del Continente ha aumentado y adquirido una proporción mayor en 1980 y su capacidad de importación se ha incrementado sustancialmente, ascendiendo a 100 mil millones de dólares en 1981. Es preciso comprender la importancia de esa modificación para estar en condiciones de reflexionar sobre la capacidad de negociación que América Latina ha conquistado en sus relaciones con Ios Estados Unidos. La exportación de petróleo por ese continente introduce una nueva dimensión en sus relaciones económicas del futuro.

\section{Relaciones económitcas con Europa Occidentat}

EI estudio de las relaciones económicas entre América Latina y Eu. 
Gonzalo Martner G. / América Latina dentro del orđen económico...

ropa Occidental es de gran interés. Se produce una extraña paradoja: pese a que la experiencia de los últimos decenios no contiene muchos aspectos positivos de cara al futuro, hay un potencial de intercambio que algunos economistas europeos están empezando paulatinamente a reconocer.

La CEE ha sido históricamente el segundo mercado para las exportaciones latinoamericanas. En 1981, éstas ascendían a $19.250 \mathrm{mi}-$ Ilones de dólares, o sea el 16\% de las exportaciones latinoamericanas totales. La CEE vendió a América Latina por un valor de unos 19.435 millones de dólares, esto es, el $15 \%$ de las importaciones latinoamericanas totales. Pero ese intercambio ha sido deficitario para América Latina, ascendiendo a 3.050 millones de dólares entre 1977 y 1981.

Durante los dos últimos decenios la situación se ha deteriorado. En 1963, Ias exportaciones latinoamericanas representaban el 29,7\%\% de sus exportaciones totales, según el Acuerdo General sobre Aranceles Aduaneros y Comercio (GATr). Diez años después, en 1973, ese porcentaje había bajado al 22,71\% y en 1981 era tan sólo del $16,4 \%$, como se indicó antes. Las importaciones de América Latina procedentes de los países de la CEE eran del $24,9 \%$, del $22,3 \%$ y del $15,3 \%$ en esos mismos años ${ }^{15}$.

La disminución de las exportaciones latinoamericanas a la CEE es el resultado de varios factores: 1) un fuerte crecimiento de la integración del comercio intraeuropeo: en 1962, éste representaba el $40 \%$ de las importaciones de los Nueve y el crecimiento progresivo durante los siguientes años eleró dicho porcentaje al $52.6 \%$ en 1972, estabilizándose en alrededor de un 50\% en el curso de los años siguientes. Si se excluye al petróleo, ese porcentaje sería del $57 \%$ en 1972 y del $56 \%$ los años posteriores; 2) el aumento de las importaciones de la CEE procedentes del Japón (que representaban el $0,9 \%$ en 1962 y el 2,4\% en 1978) y de países como Grecia, España y Portugal (que aumentaron del $1,7 \%$ al $2,4 \%$ durante ese mismo período). Pero las importaciones procedentes de países exportadores de petróleo han aumentado de modo espectacular, pasando del $9 \%$ entre 1962 y 1973 al $16 \%$ entre 1974 y 1977 . El comercio entre la CEE y los países de Asia y el Cercano Oriente se ha incrementado, del 6\% en 1962 al $10 \%$ en 1978; 3) la política agrícola de la CEE, que ha sido uno de los principales factores determinantes de la disminución del comercio entre América Latina y Europa; por una parte ha habido una integración intraeuropea $y$ un aumento de la producción agrícola, y por otra, medidas de protección y subvenciones. Tal política ha afectado al trigo, la carne, el aceite, los productos lácteos y las materias primas agrícolas, reduciéndose

${ }^{15}$ SELA, "Relations between Latin America and the European Communities". Buenos Aires, abril de 1983, p. 4. 
significativamente la parte correspondiente a los productos latinoamericanos; 4) la política de la CEE en el sector de los textiles y en el de la siderurgia, que ha afectado igualmente a algunos países latinoamericanos exportadores; y 5) la concesión de un trato preferencial a los países de la Convención de Lomé.

Los factores mencionados más arriba han llevado a los latinoamericanos a afirmar que Europa no tiene un interés sustancial en incrementar su comercio con América Latina. Aparentemente esta postura ha sido compensada en el plano político, en el cual Europa da pruebas de cierta sensibilidad ante los esfuerzos democráticos en América Latina.

La posición europea ha sido expresada en términos precisos por el señor Albrecht von Gleich:

The hypothesis of Europe being an alternative option for Latin America as against the' Unhted States is based more on emo tional than on factual grounds. The predominant role of the us cannot play off Europe against the us".

"It is often argued that Latin America is neglected by Europe due to latter's lack of interest. Partly because of the lack of specific and differentiated knowledge on Latin America as a whole is subject to criticism mainly by European political leaders, a fact that makes governamental decisions on economic measures in favour of Latin American countries sometimes quite difficult"16.

Esa corriente de opinión sostiene que hay obstáculos importantes que sería preciso salvar para poder desarrollar las relaciones económicas entre Europa y América Latina. En primer lugar, el conocimiento concreto de la realidad latinoamericana por los europeos y, por otra parte, la falta de precisión de los latinoamericanos en sus ofertas de intercambio. También se pone en tela de juicio la hipótesis de la complementariedad de las economías: las industrias de América Latina están compitiendo con las industrias europeas en mercados de ultramar tradicionalmente dominados por los europeos; la autosuficiencia alimentaria de Europa sería otra limitación importante. La estructura de las exportaciones latinoamericanas constituiría otro factor limitativo, así como las prácticas comerciales insuficientes de América Latina. Aparentemente los gobiernos latinoamericanos y el sector privado no protegen a sus instituciones de investigación y desarrollo y lo que esto significa es que la cooperación tecnológica de los países europeos no está suficientemente protegida. Otra limitación capital es la deuda externa

1ovéase "Some comments on the present relationships between Latin America and the European Community", p. 1, 1979. 
Gonzalo Martner G. / América Latina dentro del orden económico...

de los países latinoamericanos y la falta de confianza en materia financiera.

Esa posición pesimista no es compartida por todos los expertos europeos. Por ejemplo, el señor Bernard Lietaer, en su obra titulada "Le grand jeu Europe-Amérique Latine", ${ }^{17}$, pone de relieve que la presencia de la banca europea y el problema de la deuda latinoamericana en el contexto de la degradación global de las relaciones Norte-Sur crearán condiciones nuevas que obligarán a los europeos a reconsiderar su posición mediante una estrategia que califica de "diagonal" entre Europa y América Latina.

Los argumentos aducidos por el señor Lietaer ${ }^{18}$ son los siguientes: Europa es Ia región más vulnerable del mundo industrializado, porque depende de la importación de materias primas. Bien es verdad que en 1971 el Japón era más vulnerable todavía, puesto que importaba el $34 \%$ de sus materias primas y Europa el $31 \%$, pero en 1981 el Japón había reducido dicho porcentaje a menos del $30 \%$ gracias a su política de promoción de productos de gran valor añadido que contienen pocas materias primas, como ocurre en el caso de la electrónica, de los autómatas, de la óptica, etc. Europa habría seguido, por su parte, una política distinta e importaba en ese momento más del $50 \%$ de sus materias primas, la mayor parte de ellas de países del Tercer Mundo. Como consecuencia de ello, Europa es más vulnerable y debe tratar de amoldar su política en fun. ción de los países en desarrollo.

En la esfera de la tecnología, la industria europea tiene que competir con los países recientemente industrializados y habrá que encontrar una fórmula de armonización en el futuro. Las inversiones europeas en América Latina aumentaron en el curso del decenio de 1970 y superan a las de los Estados Unidos en el cașo del Brasil.

La crisis de la economía latinoamericana e incluso de la economía europea brindan la posibilidad de emprender un diálogo más creador entre América Latina y Europa en los años venideros. El aspecto dramático es la deuda exterior latinoamericana y su importancia para los bancos europeos puede ofrecer la ocasión para iniciar un diálogo nuevo entre los países europeos y los países latinoamericanos. Cierta tendencia democrática que se manifiesta en América del Sur (Bolivia, la Argentina, el Perú, el Uruguay, el Brasil y otros más), por una parte, y, por otra, cierta progresión de algunos países europeos hacia la izquierda (Francia, Grecia, España, Portugal, Italia, Suecia y Austria), pueden crear un clima político más positivo para ese nuevo diálogo, que podría conducir a una reorganización del actual orden mundial en conjunto.

17Publicada por Presses Universitaires de France, 1981, Parls.

${ }^{18}$ Ibid, p. 15. 


\section{RELACIONES EGONÓMICAS GON EL JAPÓN}

Las relaciones económicas entre América Latina y el Japón han cambiado en el curso de los 20 últimos años. Sus intercambios comerciales han aumentado y se han diversificado paulatinamente.

En 1981, América Latina exportó al Japón el 5,1\% de sus exportaciones totales e importó de él el 7,3\% de sus importaciones totales. En el decenio de 1960, la balanza comercial era favorable a América Latina, pero en el curso del decenio de 1970 hubo un déficit comercial persistente, intensificado por la crisis petrolera.

A.mérica Latina exportó productos alimentarios (azúcar, maíz, café, etc.) en proporción decreciente (tales exportaciones representaron el $29 \%$ en 1960 y tan sólo el $14 \%$ en 1981). Las exportaciones de materias primas (mineral de hierro, algodón, cobre, etc.) también disminuyeron (del $67 \%$ en 1960 al $50 \%$ en 1970 y al $32 \%$ en 1981). El petróleo no desempeñó un papel importante hasta 1981, año en el cual las importaciones procedentes de México, el Ecuador y el Perú ascendieron al $32 \%$. Las exportaciones latinoamericanas al Japón aumentaron de 311 millones cle clólares en 1960 a 1.373 en 1970 y a 6.668 en 1981.

Las importaciones latinoamericanas procedentes del Japón están constituidas por aparatos mecánicos (el $43 \%$ en 1960, el $50 \%$ en 1970 y el $74 \%$ en 1981). Dentro de este grupo, los automóviles aumentaron del $1,7 \%$ en 1960 al $14 \%$ en 1981, y la maquinaria en general también ha aumentado xápidamente. Otro grupo de productos que importa América Latina es el constituido por los productos metálicos de acero y de hierro (alrededor del 16\%).

La importancia del mercado latinoamericano para el Japón se acrecentó entre 1960 y 1970, pero registró una disminución relativa en 1981. En ese primer año las importaciones procedentes de América Latina representaron el 6,9\% de las importaciones japonesas totales; en 1970 significaron el $7,2 \%$ y en 1981 el $4,6 \%$. En lo que respecta a sus exportaciones a América Latina, éstas representaban el $7,4 \%$ en 1960 y pasaron a representar el $6,1 \%$ en 1970 y el $6,9 \%$ en 1981 .

El crecimiento de los intercambios entre América Latina y el Japón se explica por una cierta complementariedad que ha hecho posible una diversificación de los intercambios. La inversión japonesa ha contribuido al desarrollo de la industria pesada de América Latina y de su industria química, así como al desarrollo de sus recursos naturales e incluso del sector industrial manufacturero. Las inversiones japonesas han aumentado rápidamente y totalizaban 7.349 millones de dólares en 1982; o sea, el 16\% de las inversiones japonesas en el exterior ${ }^{19}$.

\footnotetext{
${ }^{2}$ Frente al $29 \%$ en Asia y el $27 \%$ en América del Norte.
} 
América Latina es un continente semindustrializado y el Japón encauza su politica de inversión y cooperación técnica hacia la industrialización latinoamericana. En cierta medida ese tipo de política ha fracasado en el caso de los Estados Unidos y de Europa y el Japón se ha beneficiado haciendo hincapié en Ios productos intermedios y en los bienes de capital. Como resultado inmediato han crecido las exportaciones al mercado japonés de bienes transformados que se elaboran en América Latina.

El economista japonés Akio Hosono, que cuenta con una gran experiencia en América Latina, ha sostenido que ésta reviste gran importancia para la economía japonesa por dos razones: I) en América Latina hay grandes recursos naturales y un proceso de industrialización orientado hacia una población en crecimiento que la economía japonesa puede apoyar con su tecnología; y 2) exceptuados los últimos años, la economía latinoamericana ha demostrado su dinamismo y representa un mercado para los bienes de capital, los bienes de consumo y los productos químicos fabricados en el Japón ${ }^{20}$.

Para América Latina las relaciones económicas con el Japón son también importantes. La tecnología japonesa puede secundar el esfuerzo latinoamericano para la producción de bienes intermedios y de bienes de capital que no produce actualmente el continente. Dicha tecnología deberá acordar importancia para el empleo de la mano de obra, la cual es abundante en la región. Aparentemente la industria japonesa presta más atención a ese problema que los países occidentales, que tienen 10 millones de desempleados en el caso de los Estados Unidos y 12 millones en el de Europa.

Por otra parte, en el Japón hay una tradición de apoyo a las pequeñas y medianas empresas industriales, las cuales abundan en América Latina. A diferencia de lo que ocurre con la influencia que ejercen determinados países occidentales, los cuales apoyan a grandes conglomerados industriales que funcionan en condiciones monopolistas, la asistencia japonesa podría acentuar el desarrollo de la eficacia de las empresas pequeñas y medianas que obligan a las grandes a proseguir sus esfuerzos productivos. Si se piensa, en términos de una estrategia latinoamericana, que acordar la prioridad. a la producción masiva de bienes de consumo populares es indispensable para limitar el desempleo, es dable concluir que el apoyo tecnológico a las empresas pequeñas y medianas constituye una linea de acción de primera importancia. La existencia de millones de pequeñas unidades agrícolas latinoamericanas representa otro caso en que el apoyo de tecnologías idóneas resulta muy pertinente. El Japón tiene gran experiencia en el desarrollo de las tecnologías de ese género. 1983.

${ }^{90}$ Akio Hosono, "Relaciones Económicas entre Latinoamérica y Japón", Min. 


\section{RELACIONES EGONÓMIICAS GON LOS PAÍSES SOGIALISTAS de Europa Central Y del Este}

Conviene pasar revista ahora a las relaciones económicas entre América Latina y los países socialistas de Europa Central y del Este.

En 1980, las exportaciones de América Latina a dichos países representaban alrededor del 6,5\% de sus exportaciones totales. Tal porcentaje refleja un aumento progxesivo, puesto que a los países. del Consejo de Ayuda Mutua Económica (CAME) les correspondía en conjunto el $5,8 \%$ en 1970 y el $2,6 \%$ en 1955 . Por su parte, el valor en términos corrientes del intercambio total se ha multiplicado 30 veces entre 1955 y 1980 . En cuanto a las importaciones procedentes de Ios pafises socialistas, ha de señalarse que en 1980 representaban el $4 \%$, frente al $5 \%$ en $1970 \mathrm{y}$ el $1,9 \%$ en $1955^{21}$.

Al tenor de esas cifras, cabe concluir que hay una tendencia al acrecentamiento a largo plazo entre América Latina y los países socialistas; en un cuarto de siglo su participación en los intercambios totales se ha duplicado.

Ha habido, sin embargo, cambios considerables en lo que concierne al origen geográfico y al contenido de dichos intercambios, como se refleja en las estadísticas. Durante el decenio de 1950 el comercio se concentraba en la Argentina, el Uruguay y el Brasil; en cambio, en el curso de los decenios de 1960 y de 1970 el centro geográfico se desplazó a Cuba. A este país le correspondió una participación del orden del $40 \%$ en 1960, que aumentó luego, en el curso de los decenios siguientes, al $75 \%$.

También ha habido cierto auge en lo que respecta a los países andinos. Es este el caso de Golombia durante el clecenio de $1960 \mathrm{y}$ el del Perú en el curso del decenio de 1970. En 1975, el comercio andino representaba el 7,3\% de las exportaciones y el 3,2\% de las importaciones latinoamericanas efectuadas con el CAME.

Las relaciones con los países del Atlántico Sur se intensificaron nuevamente a mediados del decenio de 1970 .

En cuanto a los países socialistas, procede señalar que la influencia de la Unión Soviética ha aumentado patentemente en el marco de las exportaciones latinoamericanas al GAME, que pasaron del $20 \%$ en 1960 al $60 \%$ en 1970 y al $70 \%$ en 1980. En lo que concierne a las importaciones, la uRss aumentó su participación del 20\% a más del $70 \%$ durante ese mismo período.

El aumento del comercio de los otros países también merece ser puesto de relieve: es este el caso de Checoslovaquia, Hungria, Ia República Democrática Alemana y Polonia, pero es preciso añadir que tal aumento estuvo por debajo de la media de los paises del CAME en conjunto.

- "aifras del CAME. 
Hay un desequilibrio fundamental en los intercambios mencionados más arriba, que es un caso casi único en las relaciones comerciales internacionales: los países del CAME no pueden sufragar con los ingresos derivados de sus propias exportaciones a América Latina más que del 56 al $75 \%$ del costo de sus importaciones procedentes de ella (desproporción, sin embargo, inferior a la existente entre el CAME y los países de la ocDE). Si se deja de lado a Cuba, los países del CAME sólo han podido sufragar entre el 30 y el $50 \%$ de sus importaciones procedentes de América Latina a partir de los primeros años del decenio de 1960 (en ciertos casos tal cobertura no ha llegado siquiera al $10 \%$ ). Ese desequilibrio fundamental es, sin duda, un factor esencial a efectos de la promoción de la cooperación económica entre los países latinoamericanos y los países del CAME.

América Latina vende a éstos sobre todo materias primas y alimentarias. De lo que adquiere de ellos, aproximadamente el $70 \%$ está constituido por productos manufacturados. En el caso de sus exportaciones; sin embargo, durante los 15 últimos años ha aumentado la parte relativa de los productos agrícolas, reduciéndose la importancia de las maeerias primas al tiempo que hacían su aparición los productos manufacturados. En cuanto a las exportaciones del cAME, éstas han aumentado en volumen en sectores como el de los combustibles y las maquinarias.

Los obstáculos que dificultan el acrecentamiento del comercio entre esos dos grupos de países son importantes. El primero es la disminución de la parte relativa del comercio mundial correspondiente a ambos grupos; entre 1950 y 1980 la parte de América Latina se redujo del 11 al 5,5\% y la de los países del CAME del 11 al $8 \%$.

Conviene tener presente que, desde el punto de vista histórico, los países de Europa Central y del Este han sido siempre una región periférica en Europa, en tanto que América Latina lo era en relación con Europa Occidental y los Estados Unidos de América. En otras palabras, esas dos regiones dejadas al margen han tenido pocas ocasiones de conocerse desde hace mucho tiempo. Ahora bien, si a esto se suma el hecho de que lo que hay en el seno del came son economías planificadas, se comprenderá que no sea fácil mantener intercambios con una región tan distante e inestable como América Latina. Las diferencias tecnológicas son además enormes; así, por ejemplo, la agricultura tropical de América Latina puede difícilmente ser respaldada por la tecnología agrícola de Europa del Este. La experiencia socialista en la esfera de la industria pesada sería apenas aplicable en países que carecen de minerales y de fuentes de energía (como ocurre en el caso de Cuba, de Nicaragua y de Granada).

Las redes de comercialización, transportes y financiación comer- 
cial en América Latina están en gran parte dominadas por empresas transnacionales de los Estados Unidos de América, de Europa Occidental y del Japón. En general los países de América Latina no tienen representaciones comerciales en Europa que puedan promover Ios intercambios de forma sistemática. De entrada, no hay una estrategia latinoamericana a largo plazo para racionalizar y ampliar el comercio y la cooperación con los paf́ses del CAME; tampoco hay una infraestructura de apoyo a tales intercamb:os.

Las tensiones crecientes entre el Este y el Oeste que se han puesto de manifiesto en el presente decenio inducen a pensar que no desaparecerán los obstáculos mencionados precedentemente. Del mismo modo, el nivel de endeudamiento con los países industrializados de economía de mercado, por parte tanto de los pafses del CAME como de los países latinoamericanos, no permite prever una intensificación de las relaciones entre Américá Latina y el CAME. Como se dijo anteriormente, es preciso considerar la posibilidad de equilibrar esos intercambios como un campo capaz de generar progresos. Resulta imposible que los países del CAME, cuyo endeudamiento externo es enorme, puedan seguir sosteniendo indefinidamente tal desequilibrio. Sin duda se podrá resolver gran parte de ese problema si los países socialistas mejoran su potencial de oferta, es decir, si sus productos destinados a la venta resultan más competivos en el mercado, desde el punto de vista de la calidad y del precio, y si además los países latinoamericanos se encuentran en condiciones de adquirir más de Europa Central y Oriental; en ese caso dichos productos sustituirían a los procedentes de otras regiones.

En todo caso, las proyecciones de la economía mundial a nuestro alcance muestran que la tasa de crecimiento de los países del CAMre, pese a haber sido inferior a la de los países de la OCDE durante el decenio de 1970, tendrá un dinamismo superior a la de éstos en el curso del presente decenio. Ese factor puede constituir un elemento positivo capaz de vencer ciertos obstáculos a la cooperación entre los paśses latinoamericanos y los del CAME a lo largo del decenio actual si hay una voluntad política en ese sentido.

\section{REFLEXIONES FINALES SOBRE UN NUEVO ORDEN EGONÓMICO NIUNDIAL}

Conviene ahora extraer algunas conclusiones que mueven a la reflexión. Las crisis económicas provocan estragos sociales y humanos y pueden dar igualmente origen a fuertes regresiones económicas. Es posible sacar numerosas lecciones, sin embargo, de las depresiones y de las recesiones.

La crisis del decenio de 1930 mostró cuáles eran los límites del sistema del patrón oro y puso de manifiesto la vulnerabilidad de las economías periféricas, al tiempo que revelaba a los países indus- 
trializados Ia fragilidad de sus propios niveles de vida. Se establecieron nuevas políticas de cambio, se modificó el sistema monetario y los países en desarrollo decidieron industrializarse, en tanto que los países ricos edificaban, bajo la égida del economista Keynes, el denominado "Estado benefactor".

De Ia crisis de estos años del decenio de 1980, con sus decenas de millones de desempleados sumidos en una situación dramática y un deterioro del nivel de vida que no sólo afectaba a la clase obrera sino también a vastos sectores de la clase media, es igualmente posible extraer lecciones importantes.

Resulta por cierto claro que las estrategias de apertura al mundo exterior basadas en la exportación y la obtención masiva de préstamos e inspiradas en el pensamiento monetarista no han resuelto los problemas del desarrollo, del desempleo, de la desigualdad y de la ineficacia, sino que han dado origen a una profunda recesión que, por su carácter mismo, se ha traducido en un recorte de la inflación.

En los países del "centro", ese género de política ha desembocado en algunos casos en el desmantelamiento del edificio del Estado benefactor y acrecentado las penurias que soportan los desempleados, los jóvenes, las mujeres y las personas de edad, haciendo así la vida más dura y más inhumana.

La crisis ha demostrado que el sistema monetario mundial, que implantó la privatización del crédito, ha llevado a la pérdida del control financiero y a la dilapidación de enormes recursos a través del reciclaje de los petrodólares y de una gestión errónea de la masá monetaria internacional. Hoy en día reina un caos monetario y financiero que exige con mayor urgencia que nunca la convocatoria de una nueva "conferencia de Bretton-Woods".

Esta crisis ha traído consigo la liquidación del proceso de acumulación y los efectos de la falta de inversiones resultarán perceptibles antes de lo previsto.

América Latina experimenta actualmente las consecuencias de todos los factores mencionados; es un enfermo grave que ha contraído todas las epidemias posibles por haberse expuesto a todas las experiencias que se llevaron a cabo en su curso del decenio de 1970.

Tales grandes crisis tienen pues un resultado aleccionador. Demuestran que ciertos dogmas son frágiles; gracias a ellas quedan al descubierto las insuficiencias de las políticas que intentan eludir el cambio estructural y los reajustes internacionales.

En razón de todo ello América Latina debe concentrarse actualmente en la identificación de su propio "interés latinoamericano" y concertar alianzas de indole distinta con los países del Norte dispuestos a revisar sus relaciones con ella y debe proseguir al mismo tiempo sus esfuerzos de integración latinoamericana y tercermun- 
dista en el marco de la edificación de un nuevo orden económico internacional.

Un cambio estructural de gran importancia sería el establecimiento de relaciones estrechas Sur-Sur. En efecto, de conformidad con la Declaración sobre el establecimiento de un nuevo orden económico internacional, es preciso promover una acción concertada SuxSur, es decir, una intensificación constante de la cooperación económica y técnica entre palses en desarrollo, basada en el concepto de confianza colectiva (self-reliance).

Un corolario importante del marasmo económico en los pafses del "centro" es el creciente aumento del volumen del comercio entre países en desarrollo. Es necesario recordar ciertos datos que reflejan ese hecho tan poco conocido en muchos circulos y que demuestran que la cooperación Sur-Sur no es una utopía sino por el contrario una realidad muy promisoria. En efecto, la evolución del comercio Sur-Sur permite vislumbrar cambios importantes a largo plazo. En el curso del decenio de 1970 se produjo una expansión importante que invertía la tendencia decreciente de los decenios de 1950 y 1960. Mientras que la participación del comercio mundial total correspondiente al comercio Sur-Sur, que entre 1955 y 1970 había disminuido del 6,2\% al 3,5\%, empezó a aumentar a partir de 1971 hasta llegar a ser del 6,1\% en 1979:2. Una tendencia similar se esboza en lo que concierne a la importancia relativa del comercio Sur-Sur respecto del comercio total del Tercer Mundo: el porcentaje de las exportaciones Sur-Sur, que entre 1955 y 1970 había disminuido del $24 \%$ al $20 \%$, empezó a aumentar en el curso del decenio de 1970 hasta alcanzar el $25 \%$ en 1979. La evolución es la misma en el caso de las importaciones Sur-Sur.

Por consiguiente, el Tercer Mundo parece ser ahora ya más competitivo en el sector de los productos manufacturados. Las exportaciones de éstos se concentran, empero, en unos pocos países exportadores, como por ejemplo Hong-Kong, República de Gorea, México, el Brasil, la India, Singapur y Malasia. Esos países encuentran en empresas multinacionales el apoyo necesario para su comercio, pero como contrapartida son manipulados a menudo por ellas. Para poder alcanzar la meta fijada en Lima por los países en desarrollo, que es la de exportar el $25 \%$ de los productos manufacturados mundiales antes del año 2000, sería indispensable que otros países en desarrollo y no tan sólo los siete citados exportasen productos manufacturados y que el comercio Sur-Sur de esos productos fuese aumentando paulatinamente.

Varios factores explican el crecimiento acelerado del comercio Sur-Sur. Uno de ellos es la crisis económica de que han sido presa

20Yéase UNCTAD, "El comercio entre los países en desarrollo por principales grupos de productos de la cucI y por regiones", TD/Ba.7/45, 21 de mayo de 1981. 
los países industrializados y que se ha traducido en una tasa de crecimiento inferior a la de los países en desarrollo. La recesión del "centro" se ha traducido en una reducción de la demanda de productos importados procedentes de la "periferia" y ha conducido a un "proteccionismo" mayor en favor de sus industrias nacionales. Por otra parte, los países en desarrollo tienen una gran población; representan un enorme potencial comercial interno y tienen un gran número de necesidades por satisfacer. Como se ha visto, su tasa de crecimiento ha sido más elevada que la de los países industrializados en el curso del decenio de 1970 , Io que les ha permitido ofrecer entre sí mercados de compra más activos. Lógicamente el alza de los precios del petróleo ha contribuido a que ello ocurra, en particular al acrecentar el poder de compra, en dólares, de unos I5 países en desarrollo. Esto constituye un viraje en redondo en relación con los decenios precedentes, durante los cuales los países en desarrollo no disponían de liquideces suficientes para adquirir, unos de otros, diversas mercancías.

En América Latina, las experiencias de cooperación Sur-Sur no son nuevas; las experiencias hechas por Ia ALALC (la actual ALADI), el Pacto Andino, el Mercado Común Centroamericano, la CARIcom, el SELA y las asociaciones de productores de azúcar y de bananos, asf como las empresas de navegación, de abonos, etc., han tenido resultados positivos. Se estima que en 1980, pese a las dificultades, el comercio intralatinoamericano representaba casi el $16 \%$ de su comercio total. Pero no hay la menor duda de que queda mucho por hacer.

En ese sentido, es preciso señalar que el Consejo Latinoamericano del SELA ha propuesto en 1982 una orientación Sur-Sur en el marco de su Estrategia de Seguridad e Independencia Económica de América Latina. Por primera vez en un documento firmado por los gobiernos de América Latina se declara textualmente:

"En el actual contexto de crisis económica generalizada, de creciente proteccionismo de parte de los centros para ciertos productos y de liberalización selectiva del comercio para otros - de tal manera que la protección efectiva aplicada a las importaciones procedentes de los países en desarrollo es mayor que la aplicada al comercio entre países industrializados- hace aconsejable para América Latina analizar a fondo las posibilidades de diversificar y reorientar su comercio, en primer lugar, entre los propios países de la región, y en seguida, hacia el resto de los países en desarrollo".

Con el objeto de reforzar esa orientación conceptual, el documento relativo a la Estrategia señala que en un estudio reciente de la Secretaría Permanente del SELA ${ }^{23}$ se puso de manifiesto que "una

"Doc. SP/C.A.RA/r.o/DT. No 5, "Posibilidades de reorientación del comercio exterior argentino hacia los paises latinoamericanos". 
parte de los tres mil millones de dólares de exportaciones argentinas dirigidas hacia los países que le aplicaron sanciones económicas durante el reciente conflicto del Atlántico Sur, podrían llegar a ser absorbidas por los países latinoamericanos, dado que éstos importaban en su conjunto y de los mismos rubros, veinticinco veces más de lo que Argentina exportaba a los países que le aplicaron sanciones. Inversamente, del lado de las importaciones, quedó en evidencia que más de seis mil millones de exportaciones argentinas procedentes de esos países tamb:én podrían, en un porcentaje elevado, ser provistas por países latinoamericanos que ya cuentan con una importante capacidad de exportación, o de producción, de los mismos productos que Argentina importa".

Todo esto significa que América Latina no está inactiva y que no ha dejado para "mañana" una concertación sobre la cooperación Sur-Sur que lleva implícita una nueva opción a largo plazo para el desarrollo de América Latina.

La importancia para América Latina de contar con una opción es evidente. El continente ha acumulado la mayor deuda externa hasta ahora conocida y será preciso reembolsarla durante los próximos decenios. Los modelos económicos de desarrollo como el de la sustitución de importaciones y la apertura a los mercados externos acompañadas de una política monetaria y fiscal restrictiva han demostrado su insuficiencia y traído consigo el estancamiento del desarrollo en estos primeros años del presente decenio. Dadas esas condiciones, América Latina tiene necesariamente que prever su futuro teniendo en cuenta el hecho de que hay otro reto por afrontar: se trata del hecho innegable de que entre hoy en día y el año 2000 , América Latina tendrá 250 millones de habitantes más. La magnitud de problemas de esa índole es lo que exige una estrategia nueva para la transformación del orden interno de cada país latinoamericano que vaya acompañada de un auténtico proceso de integración económica intralatinoamericana, todo ello en el marco de un proceso de articulación nueva de la economía americana en el contex. to global de la economía mundial, es decir, en el contexto de un nuevo orden mundial. 